\title{
POLÍTICAS PÚBLICAS DE INFORMAÇÃO E INTELIGENCIA COLETIVA: \\ os desafios e as possibilidades para a democratização da informação
}

\section{PUBLIC POLICIES ON INFORMATION AND COLLECTIVE INTELLIGENCE: the challenges and possibilities for the democratization of information}

\author{
Angela Halen Claro Franco ${ }^{1}$ \\ Angela Maria Grossi Carvalho \\ Plácida Leopoldina Ventura Amorim da Costa Santos ${ }^{3}$
}

\begin{abstract}
RESUMO
0 paradigma social da informação apresenta desafios múltiplos para o tempo do conhecimento interativo da Ciência da Informação, principalmente no que diz respeito ao aproveitamento da inteligência coletiva nos ambientes digitais. Nesse contexto, a inteligência coletiva se manifesta como proposta que visa 0 aproveitamento das habilidades individuais em prol do desenvolvimento de um Espaço do saber. A dotação de infraestrutura tecnológicas e competências digitais para a inserção dos indivíduos nesse espaço requer a instauração de políticas públicas eficientes para a área da informação. Sendo assim, por meio da análise exploratória e descritiva, pretende-se aproximar as políticas de informação à inteligência coletiva. Observou-se que os ideais de democratização da informação são comuns aos dois campos, e que a definição de políticas públicas de informação consistentes é alternativa viável para a realização do Espaço do saber e, por conseguinte, para a valorização da inteligência coletiva.
\end{abstract}

Palavras-chave: Inteligência coletiva. Políticas públicas. Políticas públicas de informação. Tecnologias da informação e comunicação.

\begin{abstract}
The social information paradigm presents multiples challenges for the interactive knowledge time of Information Science, especially whit regard to the use of collective intelligence in digital environments. In this context, the collective intelligence manifests itself as a proposal that aims at harnessing individual skills for the development of a Knowledge space. The provision of technological infrastructure and digital competences for the insertion of individuals in this space requires the establishment of efficient public policies for the information area. Therefore, through the exploratory and descriptive analysis, it is intended to bring information policies closer to collective intelligence. It was observed that ideals of democratization of information was common to both fields, and that defining consistent public information polices is viable alternative for the realization of the Knowledge space, and consequently for the valorization of collective intelligence.
\end{abstract}

Key words: Collective intelligence. Public policies. Information public policies. Information and communication technologies.

Artigo recebido em 18/01/2019 e aceito para publicação em 12/03/2019

1 Doutorado em Ciência da Informação pela Universidade Estadual Paulista Júlio de Mesquita Filho, Brasil. Bibliotecária-Documentalista do Instituto Federal de Educação, Ciência e Tecnologia de São Paulo, Brasil. E-mail: angelahalen@gmail.com.

2 Doutorado em Ciência da Informação pela Universidade Estadual Paulista Júlio de Mesquita Filho, Brasil. Professor Assistente Doutor da Universidade Estadual Paulista Júlio de Mesquita Filho, Brasil. E-mail: angela@carvalho.jor.br.

3 Doutorado em Lingüística pela Universidade de São Paulo, Brasil. Livre-docente em Catalogação pela Universidade Estadual Paulista Júlio de Mesquita Filho, Brasil. Docente permanente do Programa de Pós-Graduação em Ciência da Informação da Universidade Estadual Paulista Júlio de Mesquita Filho, Brasil. E-mail: placidasantos@gmail.com. 


\section{INTRODUÇÃO}

A informação é um fenômeno transversal. Ela perpassa diferentes contextos históricos, e se apresenta dinamicamente no cerne da vida em sociedade. A dimensão do fenômeno informação pode ser compreendida por meio da proposta dos espaços antropológicos. Esses, são sistemas de valores em que um mesmo fenômeno pode ser compreendido de maneiras diferentes, a depender do espaço em que esse fenômeno se manifesta (LÉVY, 2015).

0 olhar sobre a trajetória da humanidade mostra os diferentes enfoques dados à relação do humano com a informação. A cada relação com o fenômeno, novas técnicas e tecnologias foram adotadas para a preservação, uso e disseminação da informação. Nessa perspectiva de espaços antropológicos, compreende-se que o espaço atual, onde as potencialidades intelectuais carecem de ser exercidas de forma permanente, e as atividades de coordenação de ações movidas por coletivos inteligentes tornamse relevantes, é denominado de Espaço do saber (LÉVY, 2015). 0 que norteia e define esse espaço é a inteligência coletiva. Nela estão as oportunidades de aproveitamento dos saberes das comunidades, e da coordenação desses saberes a partir do uso das tecnologias da informação e comunicação. Dessas tecnologias, a que permite a reunião de indivíduos em um lugar comum é a Internet. 0 objetivo central da proposta da inteligência coletiva é 0 alcance da igualdade social a partir da valorização dos saberes individuais em prol da coletividade e a democratização dos saberes.

A cada enfoque dado à informação novas compreensões acerca do fenômeno foram incorporadas pela Ciência da Informação. Ora as preocupações dessa ciência incidiram mais fortemente sobre a prerrogativa objetiva da informação, sob seu aspecto físico; e ora sob as necessidades de passagem das informações dos estoques para as realidades dos sujeitos por meio de fluxos, sendo observadas as formas que os processos informativos podem transformar os sujeitos.

A cada mudança de paradigma é definido um novo tempo para Ciência da Informação. 0 momento caracterizado pelo paradigma físico da informação (CAPURRO, 2003) é denominado de gerência da informação (BARRETO, 2002, 2008). Já o momento de enfoque dado pela Ciência da Informação ao paradigma cognitivo (CAPURRO, 2003) é compreendido como tempo da relação informação e conhecimento (BARRETO, 2002, 2008).

0 contexto do Espaço do saber, onde os coletivos inteligentes pensam e atuam para 0 compartilhamento de recursos, para a cooperação na construção de informações e conhecimento e para 0 empreender ações coletivas em ambientes digitais, altera aspectos da condição da informação e 
POLITICAS PÚBLICAS DE INFORMAÇÃO E INTELIGÊNCIA COLETIVA: os desafios e as possibilidades para a democratização...

da comunicação, e exigem um olhar dinâmico por parte da Ciência da Informação. A ênfase no contexto social dos indivíduos para a definição de sistemas de recuperação da informação (ALMEIDA et al., 2007) caracteriza o período atual, e define o paradigma social da informação (CAPURR0, 2003) e 0 chamado tempo do conhecimento interativo (BARRET0, 2002, 2008).

Os desafios para a consolidação do Espaço do saber por meio do aproveitamento da inteligência coletiva são tão complexos e dinâmicos quanto a multidão de sujeitos e conteúdos que povoam esse espaço. Em se tratando do contexto nacional, existem questões de base ainda não resolvidas, como por exemplo, o acesso à infraestrutura tecnológica adequada, acesso à Rede, e a alfabetização digital para utilização das tecnologias e recursos.

Nesse sentido, a Ciência da Informação no tempo do conhecimento interativo, tem a responsabilidade de pensar nos novos contornos da informação, a partir da necessidade de provimento de subsídios estruturais tecnológicos e competências info-digitais. Isso se faz necessário para que as informações construídas em ações de inteligência coletiva sejam de acesso comum, para que mais indivíduos tenham acesso aos recursos disponíveis no Espaço do saber, e para que os sujeitos integrantes desse espaço tornem-se autônomos quanto ao uso crítico das tecnologias e recursos informacionais existentes nesse espaço.

Assim, questiona-se como, em termos fundamentais, o Espaço do saber tornar-se exequível, e como as potencialidades existentes no aproveitamento da inteligência coletiva podem ser atingidas. A quem caberia, então, às preocupações acerca da informação como bem e direito dos indivíduos?

A garantia de fornecimento das condições fundamentais aos indivíduos de uma sociedade se dá por meio de ações do Estado para a criação e implantação das chamadas políticas públicas. Para Souza (2006), política pública é um campo de conhecimento que objetiva colocar o governo em atividade, e/ ou analisar essa atividade, e a medida do necessário, sugerir alterações para o rumo ou curso dessa ação. A definição de políticas públicas ocorre quando os governos democráticos transformam suas propostas eleitorais em programas e ações que podem surtir resultados ou alterações no mundo, afirma Souza (2006).

A política pública é um campo integrativo, que reúne diferentes unidades em um todo organizado, mostra Souza (2006). Isso implica no fato de que o campo pode ser objeto de análise de várias áreas do conhecimento, mesmo tendo ele se originado das Ciências Políticas (SOUZA, 2006). A compreensão da política pública ser um campo de caráter holístico não significa que essa necessite de coerência metodológica e teórica, mas sim que é um campo que comporta olhares múltiplos (SOUZA, 2006). 
As políticas públicas podem objetivar diminuir os desníveis existentes em algum dos deveres do Estado em relação à população. As políticas com enfoque na saúde, por exemplo, visam garantir aos cidadãos cuidados de prevenção e promoção da saúde, assim como as políticas de educação visam garantir que todos os indivíduos tenham direito de acesso a todos os níveis educacionais promovidos pelo Estado. 0 ideal seria que as políticas públicas não apenas provessem a diminuição dos desníveis, mas que planificassem as diferenças existentes, de forma a garantir a equidade e isonomia entre os cidadãos.

Nesse sentido, como afirma Souza (2006), num regime democrático, as políticas públicas dizem respeito à ação coletiva, e à distribuição de bens que são coletivos. Ora, não seria então a informação um bem coletivo que precisa ser amplamente distribuído?

Entende-se que a responsabilidade de assegurar acesso aos recursos e tecnologias informacionais também pode ser assumida pelo Estado por meio das políticas públicas de informação. Nesse sentido, pretende-se discutir as aproximações entre o campo das políticas públicas de informação e o contexto do Espaço do saber, em especial no que se refere a instauração e manutenção do ideário da inteligência coletiva.

Para tanto, por meio da análise exploratória e descritiva, conduzida pelo aspecto documental, pretende-se discorrer sobre como o ideário da inteligência coletiva envolve as propostas de equidade para 0 acesso aos recursos informacionais disponíveis no Espaço do saber; apresentar o perfil brasileiro quanto ao acesso às tecnologias da informação e comunicação; e compreender o propósito das políticas de informação voltadas às tecnologias da informação e comunicação.

\section{INTELIGÊNCIA COLETIVA}

Compreender um espaço, do ponto de vista antropológico, baseado no saber requer um olhar sobre o que se compreende como saber. Na perspectiva de Lévy (2015), saber é o que emerge das relações sociais, do contato entre indivíduos. É diferente da competência e do conhecimento. Competência refere-se à relação do humano com as coisas, ao passo que o conhecimento é aquilo que se adquire na relação do humano com signos e informações (LÉVY, 2015). Assim, entende-se que 0 saber é uma atividade relacional e social.

Por essa razão, considera-se que o aproveitamento da inteligência coletiva se faz relevante e indispensável para a existência do Espaço do saber. Isso porque, a inteligência coletiva é a inteligência distribuída, que necessita ser amplamente valorizada, e posta em sinergia. 
POLÍTICAS PÚBLICAS DE INFORMAÇÃO E INTELIGÊNCIA COLETIVA: os desafios e as possibilidades para a democratização...

A colocação das inteligências distribuídas em sinergia, ou seja, em associação e acordo, pode ser realizada pela utilização das tecnologias da informação e comunicação. Tais tecnologias possibilitam um aumento na produção de informação, e facilitam as formas de coleta, processamento, armazenamento, recuperação e comunicação da informação (MÊGNIGBÊTO, 2010).

0 ciberespaço é a dimensão estrutural que abriga o Espaço do saber; é um espaço móvel e não geográfico, que reúne informações, os sujeitos que alimentam esse universo, e a infraestrutura material da comunicação digital (LÉVY, 2000).

A predominância das tecnologias da informação em todos os setores da sociedade tem feito com que os sistemas de informação outrora compostos apenas de bibliotecas, arquivos, centros de documentação e museus, se expandam (MÊGNIGBÊTO, 2010). Os estoques de informação, antes delimitados e restritos, passam a ser desterritorializados e difusos (BARRET0, 2009).

Um dos fatores diferenciais desse contexto diz respeito aos produtores das fontes de informação consumidas pela sociedade. Se antes os sistemas de informação eram alimentados por conteúdos de editoras, de universidades ou centros de pesquisa, e que levavam tempo até serem produzidos e disponibilizados à comunidade, hoje as fontes de informação mais populares são alimentadas pelo sujeito comum, que instantaneamente gera conteúdo para Internet de qualquer lugar com acesso à rede (MÊGNIGBÊTO, 2010).

Os geradores de conteúdo para Internet, por meio de práticas grupais, ainda que não propositalmente, fazem uso da perspectiva da inteligência coletiva em diferentes formas de manifestações. Tais manifestações seguem uma dada escala de dificuldades, a qual está diretamente relacionada com o nível de comprometimento dos indivíduos participantes da ação com o grupo a que pertencem. Do nível mais baixo para o mais elevado, tem-se: o compartilhamento, a cooperação, a produção colaborativa e a ação coletiva (SHIRKY, 2012). 0 compartilhamento é a atividade baseada na divulgação de conteúdos gerados pelos próprios sujeitos produtores, ou na replicação de informações. Já a cooperação tem por princípio a geração de identidade de grupo a partir do conhecimento de quem são os indivíduos disponíveis para a ação; ela requer a capacidade de compreender, e demonstrar-se receptivo ao outro para ações conjuntas (SENNETT, 2015). A forma mais intensa da cooperação é a produção colaborativa. Nela as atividades produtivas são pautadas na negociação e na reciprocidade (SHIRKY, 2012). A ação coletiva, como manifestação mais exigente da inteligência coletiva, requer compromisso dos indivíduos, e a compreensão de que as decisões em grupo sejam tomadas como regra (SHIRKY, 2012). 
A irreversibilidade de um contexto de predominância de tecnologias da informação e comunicação moldam o perfil de uma sociedade interconectada, e que vê na Internet a chance de ter voz ativa e participativa. A predominância tecnológica, juntamente com a transversalidade da informação, favorecem a construção e consolidação desse espaço de habitação e interação denominado ciberespaço (VILLOTA ENRÍQUEZ et al., 2017). Esse espaço, que é possibilitado pela interligação advinda da Internet, e que interliga pessoas, objetos e informação, e que é indispensável à economia capitalista e informacional, é veículo de disseminação da democracia e das possibilidades de liberdade de expressão (VILLOTA ENRÍQUEZ et al., 2017).

Se as possibilidades de liberdade de expressão são amplamente valorizadas, e acionadas, muitas vezes, como justificativa de utilização de discursos inflamados em tempos de polaridades políticas e ideológicas, o exercício democrático por meio do uso das tecnologias digitais ainda está longe de ser atingido.

\section{TECNOLOGIAS DA INFORMAÇÃO E COMUNICAÇÃO: UM BREVE RETRATO NACIONAL}

As possibilidades de aumento da produção de informações propiciadas pelo uso das tecnologias da informação e comunicação, a partir do aproveitamento da inteligência coletiva, soam como possibilidades democratizantes se pensadas na perspectiva de que 0 acesso aos recursos tecnológicos e à Internet são comuns à população.

Entretanto, sabe-se que, conforme dados apresentados pela pesquisa TIC Domicílios referente a 2016, realizada pelo Comitê Gestor de Internet no Brasil (2017), 0 acesso aos equipamentos de tecnologias da informação e comunicação não abrangem a totalidade da população. Considerando os equipamentos com maior probabilidade de permitir acesso à Internet, apenas 22\% dos domicílios brasileiros possuem computador de mesa, 29\% possuem computador portátil, e 17\% possuem tablet. A posse de celulares já representa maior disseminação nos domicílios, uma vez que $93 \%$ da população entrevistada tem esse dispositivo. Se considerada a série histórica dos dados, é curioso observar que a partir de 2008 a diminuição do uso de computadores de mesa coincide com o aumento de computadores portáteis nos domicílios brasileiros.

Os indicadores relacionados ao acesso à Internet nos domicílios mostram que 54\% da população possui acesso à rede, e 46\% não. A distância entre a totalidade dos domicílios que possuem acesso e aqueles que não possuem é mínima, fato que permite afirmar que, praticamente, metade dos domicílios 
POLITICAS PÚBLICAS DE INFORMAÇÃO E INTELIGÊNCIA COLETIVA: os desafios e as possibilidades para a democratização...

não dispõe de acesso a esse serviço. Se considerado o acesso nas áreas rurais e urbanas, a brecha criada entre os conectados e os não conectados é preocupante: $74 \%$ dos domicílios em área rural não dispõe de acesso à Internet; e 41\% dos domicílios urbanos não acessam esse serviço. Os dados são críticos, mas apresentaram melhora em relação aos anos de 2008 e 2009, nos quais apenas 18\% e 24\% dos domicílios, respectivamente, dispunham de acesso à Internet. Observando os anos de 2014 e 2015 o aumento da proporção de domicílios com acesso à Internet é quase imperceptível, haja vista que em 2014 50\% dos lares dispunham de acesso ao serviço, e em 2015 apenas 51\% dos domicílios.

Considerando as classes sociais para analisar os domicílios com acesso à Internet, a pesquisa identificou que a maioria dos domicílios das classes A e B estava conectada, representando $98 \%$ e 91\%, respectivamente, da amostra considerada (COMITÊ GESTOR DA INTERNET NO BRASIL, 2017). Ao passo que $60 \%$ dos domicílios da classe C não dispõe de acesso à Internet, e menos da metade (23\%) dos domicílios das classes DE estavam conectados.

É necessário observar também os domicílios por presença de computador e Internet. Nesse quesito a pesquisa revelou que a maioria dos domicílios, 40\%, não dispõe de computador e nem de Internet. Os domicílios que dispunham apenas de computador totalizaram 39\% da amostra. Apenas 14\% dos domicílios possuíam computador e Internet, e 7\% dispunham apenas de Internet (COMITÊ GESTOR DA INTERNET NO BRASIL, 2017). Em vista disso, pode-se inferir que a baixa quantidade de domicílios com computador e Internet ocorre pela adesão aos dispositivos móveis, e pelo uso da banda larga móvel.

Quanto à velocidade da conexão dos domicílios com acesso à Internet, a pesquisa revela que a maioria da população que dispõe de banda larga fixa possui velocidade de Internet entre 9Mbps e 10Mbps. Ademais, 35\% da população com acesso à Internet não dispõe de banda larga fixa.

A pesquisa ainda analisou os domicílios sem acesso à Internet buscando compreender o motivo para a falta do serviço. Os dados mostraram que a maioria dos domicílios, $57 \%$, não tem acesso à rede por considerar os preços para obtenção da conexão muito altos. Assim, o fator econômico ainda é o de maior implicação nesse cenário. Seguido da motivação econômica está a falta de interesse dos moradores quanto a utilização do serviço de Internet, motivo que caracteriza 49\% dos domicílios.

Mesmo com as deficiências de acesso apresentadas, o Relatório sobre o desenvolvimento Mundial de 2016 do Grupo Banco Mundial, mostra o Brasil como o quinto país com mais usuários da Internet. Em escala mundial, apenas 15\% da população tem condições econômicas de possuírem banda larga (GRUPO BANCO MUNDIAL, 2016). Os telefones celulares, utilizados por quase quatro quintos da 
população mundial, são a principal forma de acesso à Internet pelos países em desenvolvimento, como o Brasil, mostra o relatório. Apesar disso, os que não possuem telefone celular chegam a cerca de dois milhões, e 60\% da população mundial não tem acesso à rede (GRUPO BANCO MUNDIAL, 2016).

Considerando a participação na produção de conteúdo para a Internet por meio das Tecnologias da Informação e Comunicação, a quantidade de informações disponibilizadas na Web e a origem dessas publicações, obedecem ao que se vê no mundo off-line (GRUPO BANCO MUNDIAL, 2016). Os conteúdos gerados por usuários e indexados pelo Google estão em sua maioria concentrados nos Estados Unidos, Canadá e Europa, assim como a quantidade de publicações de cunho científico advindas desses países (GRUPO BANCO MUNDIAL, 2016).

Tendo em vista esse breve panorama, a seguir se pretenderá compreender o propósito das políticas de informação voltadas paras às tecnologias da informação e comunicação.

\section{POLÍTICAS DE INFORMAÇÃO PARA AS TECNOLOGIAS DA INFORMAÇÃO E COMUNICAÇÃO}

Os dados apresentados na sessão anterior apresentam as lacunas existentes entre os que possuem acesso às tecnologias da informação e comunicação e os que não dispõem. Nesse sentido, considera-se que o atual paradigma informacional e tecnológico aumenta as diferenças existentes entre 0 grau de informação que as pessoas possuem.

A informação, observada na trajetória humana como axioma para o desenvolvimento dos sujeitos tanto no nível individual como no social, no modelo atual de sociedade é o fundamento para a construção da economia, da política e da própria sociedade (CARIDAD SEBASTIÁN; MÈNDEZ RODRÍGUEZ; RODRÍGUEZ MATEOS, 2000). Considerando que a informação nesse contexto é 0 que caracteriza a sociedade contemporânea - a sociedade da informação -, entende-se que essa condição da sociedade se manifesta e é apreendida por uma parcela pouco representativa da população nacional. Nesse caso, questiona-se para quem de fato a sociedade da informação é uma realidade.

A compreensão de uma sociedade baseada na informação impõe, progressivamente, que os governos desenvolvam políticas de informação que se estendam do compromisso em ações de diagnóstico até o provimento de aparato estatal que controle e promova atividades de informação (CARIDAD SEBASTIÁN; MÈNDEZ RODRÍGUEZ; RODRÍGUEZ MATEOS, 2000). 
POLÍTICAS PÚBLICAS DE INFORMAÇÃO E INTELIGÊNCIA COLETIVA: os desafios e as possibilidades para a democratização...

0 campo da política de informação engloba duas áreas principais - as Políticas Públicas e a Ciência da Informação -, e compreende a informação como bem e como um recurso que deve ser coletado, processado, manipulado, compartilhado e gerenciado (HERNON; RELYEA, 2003).

Para Jardim (2009), as políticas públicas de informação podem ser entendidas como processos complexos que sinalizam constructos de caráter político próprios da sociedade contemporânea. Para 0 autor, a centralidade da formulação, implementação e avaliação de qualquer política pública está pautada em escolhas, confrontos e ações informacionais de relevante impacto nas várias dimensões da vida social. As preocupações acerca de políticas públicas de informação advêm do reconhecimento do Estado como entidade que acumula e produz informações, e da percepção de como tais ações do Estado incidem na sociedade atual (JARDIM, 2009).

Para Montviloff (1990), uma política de informação objetiva orientar a construção de estratégias e programas direcionados ao desenvolvimento e utilização de recursos, sistemas e serviços informacionais, podendo ela ser formulada em nível institucional, regional, nacional ou internacional. Além disso, a política de informação também se refere ao acesso e à utilização de informações e registros referentes às condutas dos governos (HERNON; RELYEA, 2003).

Hernon e Relyea (2003, p. 1300, tradução nossa) definem a política de informação como

[...] um conjunto de princípios, leis, diretrizes, regras, regulamentos e procedimentos interrelacionados que orientam a supervisão e a gestão do ciclo de vida da informação: produção, coleta, distribuição/disseminação, recuperação e uso, e retenção, incluindo a preservação da informação.

Partindo do entendimento que as políticas públicas ocorrem em conjunto de diretrizes, é válido considerar que não há uma política única e que seja suficientemente abrangente para todas as dimensões relacionadas ao provimento de informação para a sociedade. Por essa razão, na maioria das vezes, as políticas de informação abordam temas específicos (HERNON; RELYEA, 2017).

Uma política nacional de informação, seja ela de caráter único, ou composta por outras políticas, em geral abarca cinco aspectos principais relacionados à informação, afirma Montviloff (1990). Dentre eles tem-se o desenvolvimento de serviços e recursos de informação; 0 acesso e a disseminação efetiva da informação; a promoção do uso da informação; o desenvolvimento e coordenação de ações nacionais e internacionais; e a participação em ações internacionais de informação.

Caridad Sebastián, Mèndez Rodríguez e Rodríguez Mateos (2000) destacam seis funções fundamentais que as políticas públicas devem cumprir, a saber: a análise das situações existentes, com a definição do status do setor de informação de um país, a fim de estabelecer planejamentos acerca 
da realidade; a definição de objetivos para o delineamento da ação que a política deve seguir; definição dos critérios de atuação acerca dos atores que darão prosseguimento às políticas de informação, e determinação da centralização ou descentralização das políticas e cooperações; a formação de profissionais da informação para habilitação quanto ao uso efetivo das tecnologias, e fornecimento de alfabetização baseada nas redes; a promoção do uso da informação em ambiente digital; e 0 acompanhamento da política, a fim de se obter uma evolução coerente da mesma.

A criação de políticas de informação em âmbito nacional são necessárias para que haja garantia de funcionamento coerente dos recursos, dos serviços e sistema de informação; para que seja possível melhorar a complementaridade e compatibilidade entre as normativas relacionadas ao fornecimento de informação; para que se obtenha melhores respostas às implicações dos progressos relativos ao domínio da informação; e para que se obtenha participação significativa nas redes e sistemas de informação regionais e nacionais (MANTVILOFF, 1990).

Considerando a necessidade de definição de políticas públicas no contexto nacional, em especial para a melhoria das respostas às implicações dos progressos no âmbito da informação, e para a obtenção de participação significativa na rede, e para formação de profissionais habilitados para a atualização de tecnologias da informação, tem-se como exemplificação no contexto brasileiro o Programa Nacional de Apoio à Inclusão Digital nas Comunidades - Telecentros.BR, instituído pelo Decreto $\mathrm{n}^{0}$ 6.991, de 27 de outubro de 2009, e o Programa Nacional de Banda Larga - PNBL, instituído pelo Decreto $\mathrm{n}^{0} 7.175$, de 12 de maio de 2010.

0 Programa Nacional de Apoio à Inclusão Digital nas Comunidades - Telecentros.BR, fazia parte das políticas de inclusão digital do Governo Federal e tinha por objetivo possibilitar a implantação e manutenção dos telecentros comunitários e públicos do território nacional, sem interferir na continuidade e implementação de programas de natureza semelhante (BRASIL, 2009b). No escopo do Programa, telecentros comunitários e públicos são espaços que possibilitam o acesso público e gratuito às tecnologias da informação e comunicação, com o provimento de computadores conectados à Internet e disponíveis ao público para usos múltiplos, como por exemplo, para a navegação assistida e livre, e para a realização de cursos e atividades diversas para 0 desenvolvimento local (BRASIL, 2009a). 0 programa idealizado requeria participação interministerial, envolvendo aos até então denominados Ministério das Comunicações, Ministério da Ciência e Tecnologia, e Ministério do Planejamento, Orçamento e Gestão (BRASIL, 2009a).

Os últimos dados relativos ao funcionamento dos telecentros, divulgados pelo Comitê Gestor da Internet no Brasil referentes a 2013, mostram que no período da coleta das informações, haviam 3.892 
POLITICAS PÚBLICAS DE INFORMAÇÃO E INTELIGÊNCIA COLETIVA: os desafios e as possibilidades para a democratização...

telecentros em funcionamento no país, e 1.121 fora de funcionamento (COMITÊ GESTOR DE INTERNET NO BRASIL, 2014). A pesquisa considerou como telecentros em funcionamento os que dispunham de computadores com acesso à Internet no momento da pesquisa, ou em algum momento durante os três meses que antecederam a coleta dos dados. Considerando as regiões do país, observou-se que a Norte e Centro-Oeste apresentaram as menores taxas de telecentros em funcionamento, 69\% e 71\%, respectivamente (COMITÊ GESTOR DE INTERNET NO BRASIL, 2014).

A indisponibilidade do acesso à Internet nos telecentros que não estavam em funcionamento se deu por três motivos principais: a falta de instalação de computador ou Internet (22\%), a falta de manutenção ou assistência técnica (19\%), e problemas relacionados ao espaço físico ou infraestrutura (15\%) (COMITÊ GESTOR DE INTERNET NO BRASIL, 2014).

Em se tratando do tipo de conexão, a pesquisa revelou que a maioria dos telecentros em funcionamento, 53\%, dispunham de conexão à Internet via satélite, ao passo que a conexão discada e 0 uso de $3 G$ estavam entre as formas de acesso menos presentes nos telecentros em funcionamento, representando $4 \%$ cada uma das formas.

Programa Nacional de Banda Larga - PNBL teve por objetivo fomentar e expandir o uso e provimento de bens e serviços relacionados às tecnologias da informação e comunicação a fim de: ampliar a conexão à internet por banda larga; intensificar o desenvolvimento econômico e social; prover a inclusão digital; reduzir desigualdades; promover a geração de renda e de emprego; aumentar os serviços de Governo Eletrônico; proporcionar a capacitação para o uso das tecnologias da informação e comunicação e elevar a autonomia tecnológica e competitiva da população (BRASIL, 2010).

0 PNBL não obteve todos os resultados esperados. Dentre os possíveis motivos para isso destaca-se o baixo investimento, o não acompanhamento do desenvolvimento do programa, o aumento da demanda por banda larga móvel, e a falta de interesse comercial (VOITCH, 2015).

A primeira intenção de reformulação do PNBL ocorreu em 2014, como proposta de recandidatura da ex-presidente Dilma Rousseff, e denominado como Banda Larga para Todos - BLPT, o qual pretendia alcançar $90 \%$ dos municípios e 45\% dos domicílios das áreas urbanas com provimento de rede de fibra ótica, com conexão de 25 Mbps até 2018, mas que acabou por não ser oficialmente lançado (KNIGTH, 2016). Mesmo diante disso, em 2016 o Governo Federal divulgou a intenção de atualização do projeto, tendo como meta a universalização do acesso à Internet rápida no Brasil, e melhoria da conexão à Internet nas escolas e a ampliação da educação digital (MINISTÉRIO DAS COMUNICAÇÕES, 2016). 


\section{CONSIDERAÇÕES FINAIS}

A informação como bem que caracteriza e define a sociedade contemporânea requer ser apreendida pela totalidade da população, haja vista as implicações sociais, políticas e econômicas que 0 acesso ou 0 distanciamento a esse bem podem implicar.

A Ciência da Informação, como área que se preocupa com a disseminação e acesso à informação, se posiciona no campo das políticas de informação como alternativa de compreensão da informação como bem que deve ser coletado e gerido com vistas à ampliar as possibilidades de ser e de pertencer dos indivíduos inseridos na sociedade da informação.

A condição da informação no Espaço do saber é de ser conhecimento, e esse construído e valorizado por meio de práticas de inteligência coletiva em ambientes digitais. A inteligência coletiva se caracteriza como proposta democratizante no que tange 0 aproveitamento das competências individuais e o desfazimento dos papeis tradicionais de autores e consumidores de conteúdos, haja vista que todos sabem algo e podem produzir e disponibilizar informações nos ambientes digitais.

Esse ideal de democratização da informação vai ao encontro dos ideais das políticas públicas de informação. Nesse sentido, compreende-se que as políticas de informação, em especial, as voltadas para as tecnologias da informação e comunicação, são o meio de execução dos ideais da inteligência coletiva e da manutenção de um Espaço do saber.

A utilização das tecnologias da informação e comunicação expandem as possibilidades de inteligência coletiva por meio de ações direcionadas à democracia participativa, como por exemplo à formulação de leis a partir de consultas públicas e discussões abertas com a sociedade em plataformas digitais, e a utilização das redes sociais para coordenação de ações coletivas.

Os desafios para a instauração do Espaço do saber nos países em desenvolvimento como o Brasil, estão numa dimensão mais fundamental, haja vista as dificuldades quanto a posse de tecnologias da informação e comunicação e acesso à Internet. Por isso, o fato de existir uma rede mundial de computadores e informações não significa que 0 acesso a esses recursos também seja mundial (MARTINO, 2014). As intenções que visam a criação de dispositivos que aumentem o número de incluídos nessa rede é um problema político, haja vista que implica na formulação de políticas públicas que favoreçam acesso a essa rede (MARTINO, 2014).

Tais dificuldades já foram observadas pelos governos recentes, os quais intentaram a implantação de políticas voltadas ao provimento de acesso às tecnologias e redes de informação, como por meio 
POLÍTICAS PÚBLICAS DE INFORMAÇÃO E INTELIGÊNCIA COLETIVA: os desafios e as possibilidades para a democratização...

do Programa Nacional de Apoio à Inclusão Digital nas Comunidades - Telecentros.BR e do Programa Nacional de Banda Larga - PNBL. Todavia, a não continuidade dos programas e a pouca aderência dos setores envolvidos no desenvolvimento das políticas resultaram na não alteração significativa do quadro nacional da inclusão digital.

Dessa forma, considera-se ser necessário que as políticas públicas nacionais voltadas para a informação sejam contínuas e periodicamente avaliadas. É indispensável que sejam políticas de Estado e não de governo, para que não sejam descontinuadas nas mudanças de gestão. Além disso, se faz necessário que tais políticas não estejam apenas voltadas para o provimento tecnológico de recursos e bens, mas também se preocupem com a formação de agentes que propiciem às capacitações info-digitais necessárias à utilização dos recursos informacionais e tecnológicos em grau ótimo. Por isso, compreende-se que a disseminação de tecnologias digitais, como as de informação e comunicação, tem pouca probabilidade de incidir sobre 0 encerramento da brecha existente no conhecimento mundial (GRUPO BANCO MUNDIAL, 2016). Quando superados os hiatos de acesso digital haverá uma outra dificuldade a ser superada - a das capacidades digitais (GRUPO BANCO MUNDIAL, 2016). Por essa razão, a inserção plena dos indivíduos, Estado e empresas na sociedade da informação ocorre não apenas pelo acesso às tecnologias digitais, mas pela complementação em áreas que podem garantir o uso eficaz das ferramentas (GRUPO BANCO MUNDIAL, 2016). Assim, entende-se que as mudanças nos âmbitos educacional, político e cultural são mais complexas que a disponibilização de infraestrutura tecnológica para o desenvolvimento de um Espaço do saber.

Com isso, compreende-se que nesse tempo de conhecimento interativo, cabe à Ciência da Informação, por meio da participação na formulação de políticas de informação e análise crítica acerca dos propósitos e eficácias dessas políticas, instruir quanto às possibilidades de melhorias de acesso, assimilação e empoderamento informacional que estimulem a instauração e valorização de uma sociedade baseada no saber.

\section{REFERÊNCIAS}

ALMEIDA, D. P. R. et al. Paradigmas contemporâneos da Ciência da Informação: a recuperação da informação como ponto focal. Revista Eletrônica Informação e Cognição, [Marília], v.6, n.1, p.1627, 2007. Disponível em: http://www.brapci.ufpr.br/documento.php?dd0=0000005406\&dd1=ea453. Acesso em: 4 jul. 2012.

BARRETO, A. A. A condição da informação. São Paulo em Perspectiva, [São Paulo], v.16, n.3, p. 6774, 2002. Disponível em: http://dx.doi.org/10.1590/S0102-88392002000300010. Acesso em: 15 maio 2012. 
BARRETO, A. A. Uma quase história da ciência da informação. DataGramaZero: revista de Ciência da Informação, [Rio de Janeiro], v.9, n.2, abr. 2008. Disponível em: http://www.dgz.org.br/abr08/Art_01. htm. Acesso em: 24 fev. 2013.

BARRETO, A. A. Os documentos de amanhã: a metáfora, a escrita e a leitura nas narrativas em formato digital. DataGramaZero: revista de Ciência da Informação, [Rio de Janeiro], v.10 n.1, fev. 2009. Disponível em: http://www.brapci.ufpr.br/brapci/_repositorio/2017/07/pdf_ adc8910834_0000023492.pdf. Acesso em: 11 out. 2017.

BRASIL. Decreto $n^{0}$ 6.991, de 27 de outubro de 2009, que institui o Programa Nacional de Apoio à Inclusão Digital nas Comunidades - Telecentros.BR, no âmbito da política de inclusão digital do Governo Federal, e dá outras providências. Brasília: 2009a. Disponível em: http://www.planalto.gov.br/ ccivil_03/_at02007-2010/2009/decreto/d6991.htm. Acesso em: 06 out. 2017.

BRASIL. Decreto $n^{0} 7.038$, de 21 de dezembro de 2009, que altera o parágrafo único do art. $1^{0}$ do Decreto $n^{0}$ 6.991, de 27 de outubro de 2009, que institui o Programa Nacional de Apoio à Inclusão Digital nas Comunidades - Telecentros.BR, no âmbito da política de inclusão digital do Governo Federal. Brasília: 2009b. Disponível em: http://www.planalto.gov.br/ccivil_03/_at02007-2010/2009/ decreto/D7038.htm\#art1. Acesso em: 06 out. 2017.

BRASIL. Decreto $n^{0} 7.175$, de 12 de maio de 2010, que institui o Programa Nacional de Banda Larga - PNBL; dispõe sobre remanejamento de cargos em comissão; altera o Anexo II ao Decreto no 6.188, de 17 de agosto de 2007; altera e acresce dispositivos ao Decreto no 6.948, de 25 de agosto de 2009; e dá outras providências. Brasília: 2010. Disponível em: http://www.planalto.gov.br/ccivil_03/_ Ato2007-2010/2010/Decreto/D7175.htm. Acesso em: 06 out. 2017.

CAPURRO, R. Epistemologia e Ciência da Informação. In: ENCONTRO NACIONAL DE PESQUISA EM CIÊNCIA DA INFORMAÇÃO, 5., 2003, Belo Horizonte. Anais... Belo Horizonte: Universidade Federal de Minas Gerais, 2003. Disponível em: http://www.capurro.de/enancib_p.htm. Acesso em: 15 ago. 2011.

CARIDAD SEBASTIÁN, M.; MÉNDEZ RODRÍGUEZ, E. M.; RODRÍGUEZ MATEOS, D. La necesidad de políticas de información ante la nueva sociedad globalizada. El caso español. Ciência da Informação, Brasília, v. 29, n. 2, p. 22-36, maio/ago. 2000. Disponível em: http://revista.ibict.br/ciinf/article/ view/884/919. Acesso em: 29 set. 2017.

COMITÊ GESTOR DA INTERNET NO BRASIL. TIC Centros públicos de acesso 2013: pesquisa sobre 0 uso de telecentros no Brasil. São Paulo: 2014. Disponível em: http://cetic.br/media/docs/ publicacoes/2/tic-centros-publicos-de-acesso-2013.pdf. Acesso em: 11 out. 2017.

COMITÊ GESTOR DA INTERNET NO BRASIL. TIC Domicílios. São Paulo: 2017. Disponível em: http:// cetic.br/pesquisa/domicilios/indicadores. Acesso em: 05 out. 2017.

GRUPO BANCO MUNDIAL. Relatório dobre o desenvolvimento mundial de 2016: dividendos digitais - visão geral. Washington: 2016. Disponível em: http://documents. worldbank.org/curated/ en/788831468179643665/pdf/102724-WDR-WDR20160verview-PORTUGUESE-WebResBox394840B-0U0-9.pdf. Acesso em: 10 out. 2017.

HERNON, P.; RELYEA, H. C. Information Policy. In: DRAKE, M. A (ed.). Encyclopedia of Library and Information Science. 2. ed. New York: Marcel Dekker, 2003. v.2. Disponível em: https:// 
POLITICAS PÚBLICAS DE INFORMAÇÃO E INTELIGÊNCIA COLETIVA: os desafios e as possibilidades para a democratização...

books.google.com.br/books?id=GBICVdZOT6IC\&printsec=frontcover\&hl=pt-BR\&source=gbs_ge_ summary_r\&cad=0\#v=0nepage\&q=\%20Information\%20policy\%2C\&f=false. Acesso em: 29 set. 2017.

JARDIM, J. M.; SILVA, S. C. A; NHARRELUGA, R. S. Análise de políticas públicas: uma abordagem em direção às políticas públicas de informação. Perspectivas em Ciência da Informação, Belo Horizonte , v. 14, n. 1, p. 2-22, abr., 2009. Disponível em: http://dx.doi.org/10.1590/S141399362009000100002. Acesso em: 01 Out. 2017.

KNIGHT, P. 0 papel da banda larga no desenvolvimento do Brasil. In: KNIGHT, P.; FEFERMAN, F.; FODITSCH, N (Org.). Banda Larga no Brasil: passado, presente e futuro. Barueri: Novo Século, 2016. Disponível em: https://goo.gl/KVPHfp. Acesso em: 10 out. 2016.

LÉVY, P. A inteligência coletiva: por uma antropologia do ciberespaço. São Paulo: Folha de São Paulo, 2015.

LÉVY, P. Cibercultura. 2.ed. São Paulo: Editora 34, 2000.

MARTINO, L. M. S. Teoria das mídias digitais: linguagens, ambientes, redes. Petropolis: Vozes, 2014.

MÊGNIGBÊTO, E. Information policy: Content and challenges for an effective knowledge society. Author links open overlay panel. The International Information \& Library Review, [S.I.], v. 42, n. 3 , set. 2010, p. 144-148. Disponível em: < https://goo.gl/J98sdQ>. Acesso em: 02 out. 2017.

MINISTÉRIO DA FAZENDA. 0 que é o Grupo do Banco Mundial? 2017. Disponível em: http:// www.gpeari.min-financas.pt/relacoes-internacionais/relacoes-multilaterais/instituicoes-financeirasinternacionais/banco-mundial/o-que-e-o-grupo-do-banco-mundial. Acesso em: 11 out. 2017.

MINISTÉRIO DAS COMUNICAÇÕES. Governo prepara atualização do Programa Nacional de Banda Larga. Brasília, 2016. Disponível em: http://www.brasil.gov.br/infraestrutura/2016/03/governoprepara-atualizacao-do-programa-nacional-de-banda-larga. Acesso em 07 out. 2017.

MONTVILOFF, V. Políticas nacionales de información: manual sobre la formulación, aprobación, aplicación y funcionamiento de una política nacional sobre la información. París: UNESC0, 1990. Disponível em: http://unesdoc.unesco.org/images/0008/000869/086995sb.pdf. Acesso em: 29 set. 2017.

SENNET, R. Juntos: os rituais, os prazeres e a política da cooperação. 3. ed. Rio de Janeiro: Record, 2015.

SHIRKY, C. Lá vem todo mundo: o poder de organizar sem organizações. Rio de Janeiro: Zahar, 2012.

SOUZA, C. Políticas públicas: uma revisão de literatura. Sociologias, Porto Alegre, ano 8, n.16, jul./ dez. 2006, p. 20-45. Disponível em: http://www.scielo.br/pdf/soc/n16/a03n16. Acesso em: 10 de outubro de 2017.

VILLOTA ENRÍQUEZ, J. A. et al. Para uma política de informação no ciberespaço: avanços, perspectivas e desafios. Revista Digital Biblioteconomia e Ciência da Informação, Campinas, v. 15, 
n.3, p.736-757, set./out. 2017. Disponível em: https://periodicos.sbu.unicamp.br/ojs/index.php/rdbci/ article/view/8647632. Acesso em: 01 out. 2017.

VOITCH, T. B. Plano de acesso à banda larga termina sem metas cumpridas. Gazeta do Povo,

[Curitiba], 17 fev. 2015. Disponível em: http://www.gazetadopovo.com.br/economia/plano-de-acessoa-banda-larga-termina-sem-metas-cumpridas-ejzwvl9mmq1srnv6e5346eamm. Acesso em: 07 out. 2017. 